Abstracta Iranica Abstracta Iranica

Revue bibliographique pour le domaine irano-aryen

Volume 34-35-36 | 2017

Comptes rendus des publications de 2011-2013

\title{
Andrea M. Berlin, Rafael Frankel. «The Sanctuary at Mizpe Yammim: Phoenician Cult and Territory in the Upper Galilee during the Persian Period »
}

\section{Astrid Nunn}

\section{(2) OpenEdition}

Journals

Édition électronique

URL : http://journals.openedition.org/abstractairanica/41621

DOI : 10.4000/abstractairanica.41621

ISSN : 1961-960X

Éditeur :

CNRS (UMR 7528 Mondes iraniens et indiens), Éditions de l'IFRI

Référence électronique

Astrid Nunn, « Andrea M. Berlin, Rafael Frankel. «The Sanctuary at Mizpe Yammim: Phoenician Cult and Territory in the Upper Galilee during the Persian Period » », Abstracta Iranica [En ligne], Volume 34-35-36 | 2017, document 56, mis en ligne le 15 juillet 2016, consulté le 01 octobre 2020. URL : http:// journals.openedition.org/abstractairanica/41621; DOI : https://doi.org/10.4000/abstractairanica. 41621

Ce document a été généré automatiquement le 1 octobre 2020.

Tous droits réservés 


\title{
Andrea M. Berlin, Rafael Frankel. « The Sanctuary at Mizpe Yammim: Phoenician Cult and Territory in the Upper Galilee during the Persian Period \\ 》)
}

\author{
Astrid Nunn
}

\section{RÉFÉRENCE}

Andrea M. Berlin, Rafael Frankel. « The Sanctuary at Mizpe Yammim: Phoenician Cult and Territory in the Upper Galilee during the Persian Period ». BASOR, 366, 2012, p. 25-78.

La trouvaille des quatre objets votifs exceptionnels en bronze qui rendirent le site de Mizpe Yammim célèbre, remonte à 1986. Suivit une fouille, dont les AA. nous présentent la stratigraphie, l'architecture et les objets, le tout datant essentiellement de la période achéménide. Mizpe Yammim est à $12 \mathrm{~km}$ au sud-ouest de Hazor et à $35 \mathrm{~km}$ à l'est de Acco. Au sommet du tell se trouvent un grand bâtiment et un temple, tous deux protégés par un mur. Le temple consiste en une pièce barlongue de $6 \times 13.7 \mathrm{~m}$ et une seconde pièce attenante de 4,8x4,4 m. De très nombreux objets y étaient déposés : parmi eux 75 flacons phéniciens à huile fine et parfum en terre cuite, sept bijoux, cinq fibules, deux pièces de monnaies, deux poids et cinq figurines en bronze et en pierre. Outre de très nombreux ossements d'animaux et des "masses » de tessons de céramique, quelques "beaux objets » se singularisent et sont illustrés en couleur. Il s'agit d'un Osiris en bronze (cf. Ascalon), d'une petite triade en pierre avec Isis, Osiris et Horus et des quatre objets trouvés avant la fouille : trois petits bronzes animaliers (un taureau, un lion et un bélier) et surtout d'une situle en bronze. La situle égyptienne arbore des dieux égyptiens mais porte une inscription phénicienne selon laquelle cet 
objet a été dédié à Astarté. Cette situle est un indice supplémentaire pour prouver que l'aspect extérieur des dieux importait peu aux Phéniciens et que derrière les divinités à aspect étranger en Phénicie se cachaient en réalité des dieux phéniciens.

2 Vu l'origine de la céramique et l'inscription les AA. sont portés à croire que le culte était entre des mains phéniciennes. Mizpe Yammim était probablement un site fortifié de la périphérie phénicienne fondé à la fin $\mathrm{du} \mathrm{VI}^{\mathrm{e}}$ ou au début du $\mathrm{V}^{\mathrm{e}}$ au moment où les Perses attribuaient à Tyr le contrôle sur la Galilée Supérieure. La situation géostratégique ayant complètement changé, le culte fut abandonné avec la conquête d'Alexandre.

\section{AUTEURS}

\section{ASTRID NUNN}

Université de Munich 